\title{
Second-best tax policy and natural resource management in growing economies*
}

\author{
Steven P. Cassou \\ María José Gutiérrez
}

Arantza Gorostiaga

Stephen F. Hamilton

\begin{abstract}
This paper investigates the exploitation of environmental resources in a growing economy within a second-best fiscal policy framework. Agents derive utility from two types of consumption goods - one which relies on an environmental input and one which does not - as well as from leisure and from environmental amenity values. Property rights for the environmental resource are potentially incomplete. We connect second best policy to essential components of utility by considering the elasticity of substitution among each of the four utility arguments. The results illustrate potentially important relationships between environmental amenity values and leisure. When amenity values are complementary with leisure, for instance when environmental amenities are used for recreation, optimal taxes on dirty goods generally increase over time. On the other hand, optimal taxes on dirty goods generally decrease over time when leisure and environmental amenity values are substitutes. Under some parameterizations, complex dynamics leading to non-monotonic time paths can emerge.
\end{abstract}

\footnotetext{
*We would like to thank Jaime Alonso, Carlota Balestra, Carmen Arguedas and seminar participants at the Macroeconomic Implications of Environmental Policy Workshop in Vigo Spain, XV Annual Conference of the European Association of Environmental and Resource Economists (EAERE) in Thessaloniki Greece, XXII Simposio de Análisis Económico in Granada Spain, and III Congreso de la Asociación Hispano-Portuguesa de Economía del Medio Ambiente y de los Recursos Naturales (AERNA) in Palma de Mallorca Spain. We also thank the editor and two anonymous referees for helpful comments on an earlier draft of the paper. Some of this research was supported by the Spanish Ministry of Education and Science, grant number SEJ2006-12793/ECON. 2006-2009 and Basque Government grants IT-214-07 and GME0702. Cassou would also like to acknowledge the support and hospitality of Universidad del País Vasco.
} 


\section{Introduction}

The efficient design of fiscal policies that encompass the provision of environmental resources is a subject of growing importance. In many cases, the formulation of government environmental policy is set in the context of economic growth and can lead to optimal fiscal policies that evolve over time as growth occurs. Often, these policies move in one direction over time, either always increasing or always decreasing, as the forces that impact policy move in the same direction as growth occurs. However, sometimes these dynamic policies exhibit non-monotonic behavior in which policies move in one direction for a period of time, only to be reversed and move in an opposite direction. Perhaps the best known example is the Environmental Kuznets Curve (EKC), where research has provided several explanations for why various types of pollution are frequently observed to follow a non-monotonic path of rising pollution during early stages of economic development followed by subsequent declines at later stages. ${ }^{1}$ Other notable examples include fishery and forest management practices in which periods of rapid resource depletion are followed by periods of dramatically reduced harvests and resource recovery with subsequently moderated harvesting practises. It is also common for local community growth policies to provide initial tax incentives to firms migrating into a community and then later repeal them.

In this paper we investigate optimal tax policy in situations with economic growth and a fixed natural resource stock. Our primary aim is to consider how a planner armed with second best tax tools would formulate policy so as to allocate this fixed stock of environmental resource to competing production and leisure activities. To fix these ideas, consider a tract of undeveloped land that can be allocated to production or to recreation, for instance the U.S. Arctic National Wildlife Preserve, and the optimal tax treatment of products such as gasoline and diesel fuel that rely on extractive uses of the resource. The key elements of the analysis are the "dirty" good (refined petroleum extracted from a wildlife preserve), an alternative "clean" good (alterna-

\footnotetext{
${ }^{1}$ For a recent review of the EKC literature, see Dasgupta et al. (2002).
} 
tive energy sources), and environmental amenity values arising from preservation of the resource in a natural state ("use" and "non-use" values associated with wildlife preservation). Our analysis reveals that the optimal tax treatment of the dirty good depends on the degree of substitutability between the dirty good and the clean good, as well as the degree of substitutability between environmental amenity values and leisure (e.g., the ability to access a wildlife preserve for recreational uses). These elasticities allow us to identify when the various substitution patterns between goods, leisure, and environmental amenity values produce monotonic and non-monotonic patterns for optimal taxes over time.

We frame our analysis around a Ramsey (1927) model of optimal fiscal policy. This Ramsey approach was extended by Sandmo (1975) and Bovenberg and van der Ploeg (1994) to situations with externalities and is the foundation for evaluating optimal policy in static, second-best settings with non-market goods. ${ }^{2}$ As interest has grown in understanding the connection between economic growth and the environment, there is an increasing need to adapt these static optimal tax concepts into dynamic settings. ${ }^{3}$ This paper makes such a connection by applying numerical techniques for optimal tax policy pioneered in the macroeconomics literature to evaluate the implications of various elasticities of substitution in an economy with environmental resources. ${ }^{4}$

Our analysis is framed around four essential determinants of consumer utility: two types of consumption goods -one which relies on an environmental input and one which does not- leisure, and environmental amenity value. All production goods are

\footnotetext{
${ }^{2}$ For surveys of this literature, see Poterba (1993), Auerbach and Hines (2001), and Bovenberg and Goulder (2002).

${ }^{3}$ Examples of dynamic models that consider second-best tax policy with environmental externalities include Jorgenson and Wilcoxen (1993), Goulder (1995), Bovenberg and Goulder (1996), Bovenberg and de Mooij (1997) and Cassou and Hamilton (2005).

${ }^{4}$ One interesting feature of the application here is that these techniques had to be adapted to handle multiple consumption goods. A common assumption in most macroeconomic applications of dynamic optimal taxation is that a single representative good is consumed at each date. This is the case in Lucas and Stokey (1983), Judd (1985, 1999), Chamley (1986), Zhu (1992), Jones, Manuelli and Rossi (1993, 1997), Chari, Christiano and Kehoe (1994), Cassou and Lansing (1998, 2006) Aiyagari, Marcet, Sargent and Seppälä (2002) and Gorostiaga (2003, 2005). In this case, the tax rate on all consumption goods available at a particular date are implicitly equal.
} 
elastically supplied, so that taxes are always distortionary, and our focus is on how the second-best optimal tax policy evolves over time as growth alters the magnitude of the various distortions in the economy. Our main finding is that optimal tax policy in a growing economy involves distinct dynamic patterns that depend on the degree in which the various utility arguments substitute for one another. Furthermore, the degree to which these goods substitute is influenced by the tension between the use of environmental resources as an input in goods production and in the generation of amenity values, and the extent to which the amenity values are fully internalized in markets. We identify two main forces which cause the magnitude of environmental externalities, and hence the required extent of corrective taxation, to trend over time. These include the degree to which environmental amenity values are complementary with leisure and the degree to which dirty goods are complementary with clean goods.

The intuition for changes in the dynamic pattern of corrective taxes on environmental goods is as follows. In a growing economy, economic growth raises effective leisure. This means the corrective role for tax policy depends on whether increments in leisure raise or lower the demand for environmental amenities. When amenity values are highly complementary with effective leisure activities, the growth of effective leisure time facilitates consumer demand for amenities, increasing the need for corrective taxes that encourage environmental protection. The opposite is true when amenity values substitute for effective leisure, for instance if consumers enjoy spending their leisure time on the internet, as opposed to recreating outdoors. In the latter case, economic growth increases effective leisure, allowing greater substitution for amenity. Because of the reduced need for amenity, natural resources become increasing used in dirty good production, for instance printer paper, and the optimal planner facilitates this conversion by reducing taxes on dirty goods.

The degree to which dirty goods are complementary with clean goods also impacts the optimal tax policy. When dirty goods are more complementary (substitutable) with clean goods the optimal tax on dirty goods decreases (increases) over time. ${ }^{5}$

\footnotetext{
${ }^{5}$ This corroborates the finding of Lopez (1994), who demonstrates that optimal environmental
} 
These relationships arise because economic growth raises the amount of consumption goods that can be produced from a given level of inputs. When the dirty and clean goods are complementary, consumption levels increase with growth and the dirty good tax adjusts downward to encourage its production which would otherwise be inhibited because of the fixed natural resource factor of production. When the consumption goods are substitutes, the growing capability of the economy to produce clean goods reduces the social value of environmental resources in production, and this facilitates increasing taxes on dirty goods over time. For instance, if electronic files and paper files are highly substitutable, then economic growth should lead to higher taxes on paper products over time.

Our analysis also reveals that complex dynamics can emerge, including nonmonotonic relationships in the dynamic tax profile. These non-monotonic time paths tend to arise in situations where there is a high degree of substitutability among the utility arguments. Under these circumstances, for instance when leisure substitutes for forestland amenities at the same time that electronic files substitute for paper, the productive and consumptive margins for the environment evolve in common directions with economic growth. Dynamic reversals tend to require high degrees of substitution between goods, because substitution possibilities raise the likelihood that policy can produce large swings in the desired consumption allocations as the economy grows. These large swings in desired consumption allocations, in turn, can result in non-monotonic time paths for the optimal second-best tax policy variables.

The remainder of the paper is organized as follows. Section 2 presents the competitive economy and the Ramsey planner's problem. Because of the intractable nature of the model presented here, simulation techniques are used to study policy. These simulations are based on a model calibration described in Section $3 . \quad$ In Section 4, results of the numerical Ramsey solutions are presented and some general statements are derived about the influence of utility valuations on optimal policy.

taxes should rise over time when polluting and non-polluting inputs are substitutes in a single production process. 


\section{The Model}

The objective of the paper is to understand how optimal second best tax policy evolves in a growing economy with a fixed natural resource and a rich set of consumer utility arguments. Because economic growth changes the marginal valuation of the environmental resource in its alternative uses, the corrective role for taxation changes over time and these changes are impacted not only by activities that make use of the natural resource, but also activities that substitute or complement natural resource usage. To couch these issues in a reasonably transparent model, we pursue a structure in which environmental resources are converted into final goods through a process of exogenous (and neutral) technological progress.

In what follows, we first describe the growth process through which productive inputs change over time. Next, we focus on the details of the economy which is comprised of a production sector, a consumer sector, and a government sector. We consider each of these sectors in turn before formalizing the Ramsey problem at the end of this section.

\subsection{Productive resources}

We abstract from population growth and focus only on growth arising from technological progress. Let $A_{t}$ and $k_{t}$ denote the technology level and the capital to labor ratio in the economy at time $t$. Technology and the capital-labor ratio are assumed to grow exogenously according to

$$
A_{t}=(1+q) A_{t-1} \quad \text { for } \quad t \geq 0 \text {, }
$$

and

$$
k_{t}=(1+q) k_{t-1} \quad \text { for } \quad t \geq 0 \text {, }
$$

where $q$, the rate of technical change, proportionally influences productivity growth and the growth rate in the capital to labor ratio. Such would be the outcome under balanced growth. 
Productive resources are allocated across two production sectors, a dirty sector, which makes use of an environmental resource, and a clean sector that produces goods without relying on use of the environmental resource. We focus on a fixed stock of the environmental resource, for instance a tract of land that can be allocated either to production in the dirty sector or to open space. We denote this fixed stock by $d$ units, of which $d_{1, t}$ are the number of units allocated toward dirty sector production at time $t$ and $d_{2, t}=d-d_{1, t}$ are left in a natural state. We assume that units of the resource left in a natural state generate amenity values that contribute to consumer utility, whereas units devoted to goods-production do not.

\subsection{The production sectors}

Manufactured goods are produced in two production sectors. We index the producers by $j$ and distinguish them by $j=d, h$, where $d$ denotes the producers which makes use of environmental resources and we refer to as dirty producers and $h$ denotes the producers which do not and we refer to as the clean producers. Let $y_{j, t}, k_{j, t}$ and $l_{j, t}$ denote output, capital input and labor input into sector $j$ at time $t$. In each sector, output is created through the employment of physical capital, labor and land according to

$$
y_{d, t}=A_{1 d} k_{d, t}^{\alpha-\eta}\left(A_{t} l_{d, t}\right)^{(1-\alpha)} d_{1, t}^{\eta} \text { for } \quad t \geq 0,
$$

and

$$
y_{h, t}=A_{1 h} k_{h, t}^{\alpha}\left(A_{t} l_{h, t}\right)^{(1-\alpha)} \quad \text { for } \quad t \geq 0,
$$

where parameters are restricted according to $0<A_{1 j}$ for $j=d, h, \alpha \in(0,1)$ and $0<\eta<\alpha$. For simplicity we assume the production functions (3) and (4) are associated with symmetric factor shares for labor inputs and that each experiences the same rate of technological progress as governed by $A_{t}$ in equation (1). Productivity growth does not bias the economy towards either one of the two productive sectors, although sectoral productive capabilities may differ inherently according to the sectorial coefficients $\left(A_{1 d} \neq A_{1 h}\right)$. 
Each agent in the economy begins at time $t=0$ with a homogeneous endowment of land which they keep for the rest of time and an equal amount of capital $k_{0}$ which evolves over time according to (2). Capital, labor and land resources are assumed to be freely mobile. At each date, productive resources are allocated across sectors towards their highest return. This implicitly assumes that the allocation of the environmental resource between production and its natural state is a reversible decision. In equilibrium, resource mobility has the effect of equating returns across activities, so that

$$
\begin{aligned}
& r_{t}=r_{d, t}=r_{h, t}=p_{d, t}(\alpha-\eta) \frac{y_{d, t}}{k_{d, t}}=p_{h, t} \alpha \frac{y_{h, t}}{k_{h, t}} \text { for } \quad t \geq 0, \\
& w_{t}=w_{d, t}=w_{h, t}=p_{d, t}(1-\alpha) \frac{y_{d, t}}{l_{d, t}}=p_{h, t}(1-\alpha) \frac{y_{h, t}}{l_{h, t}} \text { for } \quad t \geq 0,
\end{aligned}
$$

and

$$
v_{t}=p_{d, t} \eta \frac{y_{d, t}}{d_{d, t}} \text { for } \quad t \geq 0
$$

where $r_{t}, w_{t}$ and $v_{t}$ denote the market capital rental rate, market wage rate and market environmental resource rental rate at time $t$ and $p_{j, t}$ denotes the price of output in sector $j=d, h$, at time $t$. We choose good $h$ as the numeraire, so that $p_{h, t}=1$.

\subsection{The consumer sector}

The private sector consists of many identical, infinitely-lived agents who provide capital, labor and land to the corporate sector in exchange for income used to purchase consumption goods. The representative agent acquires instantaneous utility at time $t$ through the consumption of dirty goods, $c_{d, t}$, clean goods, $c_{h, t}$, time devoted to leisure, $\left(1-l_{t}\right)$, and the amount of the environmental resource devoted to the production of amenity, $a_{t}$, through "visitation," where the amenity value of the environmental resource is related to the quantity of the environmental resource set aside from production, $d_{2, t}=d-d_{1, t}$, as described below. The utility function takes the CES form,

$$
\sum_{t=0}^{\infty} \beta^{t}\left(\varepsilon_{1} c_{t}^{\theta}+\left(1-\varepsilon_{1}\right) b_{t}^{\theta}\right)^{\frac{1}{\theta}},
$$


where $0<\beta<1$ is the discount factor,

$$
c_{t}=\left(\varepsilon_{2} c_{d, t}^{\psi}+\left(1-\varepsilon_{2}\right) c_{h, t}^{\psi}\right)^{\frac{1}{\psi}},
$$

is a composite consumption good, and

$$
b_{t}=\left(\varepsilon_{3} a_{t}^{\sigma}+\left(1-\varepsilon_{3}\right)\left[A_{t}\left(1-l_{t}\right)\right]^{\sigma}\right)^{\frac{1}{\sigma}}
$$

is an amenity-leisure composite. The share weights are restricted so that $0<\varepsilon_{i}<1$ for $i=1,2,3$, and the elasticity parameters are restricted according to $\theta \leq 1, \psi \leq 1$ and $\sigma \leq 1$. The elasticity parameters are related to the elasticity of substitution between the consumption aggregate $c_{t}$ and the amenity-leisure aggregate $b_{t}, 1 /(1-\theta)$, the elasticity of substitution between the consumption levels $c_{h, t}$ and $c_{d, t}, 1 /(1-\psi)$, and the elasticity of substitution between the amenity $a_{t}$ and leisure $A_{t}\left(1-l_{t}\right), 1 /(1-$ $\sigma){ }^{6}$ Positive values of $\phi, \psi$ and $\sigma$ arise for substitutes and negative values arise for complementary goods. The utility formulation in (8) exhibits intertemporal time separability as is commonly assumed in dynamic models; however, when $\theta<1$, $\psi<1$ and $\sigma<1$ (the usual case), the utility function does not exhibit temporal separability. As we show below, when utility does not exhibit temporal separability, optimal taxes exhibit dynamic behavior.

Amenity value arising from the quantity of the environmental resource set aside from production is allowed to have common property aspects, which reflects potentially incomplete property rights. Specifically,

$$
a_{t}=d_{2, t}^{\gamma} \bar{d}_{2, t}^{1-\gamma}
$$

where $\bar{d}_{2, t}$ is the uninternalized value of the resource amenity, and $0<\gamma \leq 1$ represents the extent of property rights. When $\gamma \longrightarrow 0$, the amount of the environmental

\footnotetext{
${ }^{6}$ Note, $l_{t} \neq 1$, since $l_{t}$ is used to denote the portion of the total time endowment spent working and $1-l_{t}$ is used to denote the total time spent in leisure. Notice also that the value of time in leisure grows at the same rate as the value of time in production. This is a common structure used to ensure balanced growth in models that do not include natural resources. The implicit assumption is that technological advances that improve the production of goods (e.g., "fish finders") lead to proportional advances in home production techniques (e.g., recreational fishing).
} 
resource an individual sets aside from production contributes negligibly to aggregate utility (a common property resource), whereas when $\gamma=1$ each individual is fully compensated for the amenity value associated with ownership of an undisturbed environmental resource. It is assumed in equilibrium that $\bar{d}_{2, t}=d_{2, t}$.

Consumers face a budget constraint given by

$$
\sum_{j=d, h}\left(1+\tau_{j, t}\right) p_{j, t} c_{j, t}=\sum_{j=d, h} r_{j, t} k_{j, t}+\sum_{j=d, h} w_{j, t} l_{j, t}+v_{t} d_{1, t}, \quad \text { for } t \geq 0,
$$

where the right hand side indicates income earned at time $t$ through the provision of inputs to the corporate sector and the left hand side indicates expenditures at time $t$ on consumption goods. Consumers take the consumption tax on good $j$ at time $t$, $\tau_{j, t}$, as exogenously chosen by the government.

We consider cases in which the government is unable to tax the externality directly. Instead, we consider environmental policy as being implemented indirectly through differences in the sectoral tax rates on clean and dirty goods, where the difference $\tau_{d, t}-\tau_{h, t}$ corresponds to a corrective tax on dirty goods in the usual Pigouvian sense.

\subsection{The government sector}

The government engages in two types of activities. First, the government purchases goods from sector $j$ at time $t$ at a level denoted by $g_{j, t} \geq 0$. These purchases are assumed to be nonproductive. Second, the government chooses a tax policy which serves both to raise revenue for financing its expenditures and to correct the externality in amenity formulation that arises when $\gamma \neq 1$. The tax instruments available for this purpose consist of a consumption tax on each of the two goods, denoted by $\tau_{j, t}$ for $j=d, h$, where a negative value for a tax may be interpreted as a subsidy. We assume the government runs a balanced budget at each date given by,

$$
\sum_{j=d, h} p_{j, t} g_{j, t}=\sum_{j=d, h} \tau_{j, t} p_{j, t} c_{j, t}, \text { for } t \geq 0 .
$$

It is assumed that nonproductive government spending grows in proportion to the total level of output according to $\sum_{j=d, h} p_{j, t} g_{j, t}=\phi \sum_{j=d, h} p_{j, t} y_{j, t}$, where $\phi \geq 0$. 
Under this restriction, spending remains a constant share of output over time in which the share, $\phi$, can be thought of as being decided in an exogenous political process. ${ }^{7}$ If $\phi=0$, then taxes serve a purely corrective role.

\subsection{Competitive equilibrium}

A competitive equilibrium for this economy consists of prices, allocations and government policy variables such that agents behave optimally as described above, the government satisfies its budget constraints and the following market clearing conditions hold. The input market clearance conditions require that capital across sectors adds up to the total capital stock,

$$
k_{t}=\sum_{j=d, h} k_{j, t} \text { for } \quad t \geq 0,
$$

the total time allocation adds up to the total time available,

$$
l_{t}=\sum_{j=d, h} l_{j, t} \text { for } \quad t \geq 0
$$

and the natural resource allocation adds up to $d$,

$$
d=\sum_{i=1,2} d_{i, t} \quad \text { for } \quad t \geq 0
$$

In addition to the input markets, the output good markets clear when

$$
c_{j, t}+g_{j, t}=y_{j, t} \text { for } j=d, h \text { and } t \geq 0 .
$$

\subsection{The Ramsey planner}

Optimal policy is described by the actions of a Ramsey planner who wishes to maximize consumer utility subject to the economy being in a competitive equilibrium. Because the capital stock grows exogenously and the government runs a balanced budget, the Ramsey planning problem in itself has no intertemporal consequences. The optimal second-best tax problem therefore reduces to a sequence of temporal optimization problems. Despite this simplification, however, the utility function is

\footnotetext{
${ }^{7}$ Alternatively, it is possible to interpret $\phi$ as an administrative loss parameter.
} 
still sufficiently complicated that closed form expressions do not arise for the demand equations. As a consequence, we solve the planner's problem numerically.

\section{Baseline Calibration}

For the baseline calibration of the model, both goods-producing sectors of the economy are assumed to be equally productive, $A_{1 d}=A_{1 h}=1$. Next, since roughly sixty percent of output in industrial nations is used to pay labor inputs, we select $\alpha=0.4$, a value widely used in macroeconomic studies. The output elasticity of the environmental resource in dirty goods production, $\eta$, is not a widely calibrated parameter in other studies. For our analysis, we use a value of $\eta=0.1$ which is the midpoint of the feasible range of $[0,0.2] .^{8}$

One of the main objectives of this study is to investigate how optimal policy varies with the degree to which utility arguments are substitutable or complementary. For the baseline case, all of these parameters are set to $\psi=\theta=\sigma=-0.1$, a value close to the natural $\log$ preference value of 0 . We assume that environmental property rights are not fully internalized and use a value of $\gamma=0.5$, which is the midpoint of the feasible range of $(0,1)$. The weights in the utility function are chosen in part to obtain a labor supply equal to one third of the time endowment, a widely used calibration point. With this objective, $\varepsilon_{2}=0.5$ is selected to place equal weights on dirty and clean goods, while $\varepsilon_{1}=0.4$ and $\varepsilon_{3}=0.1$ ensures that the labor supply allocation remained at one third of the time endowment.

We chose a government consumption rate of twenty percent of output, $\phi=0.2$, which is the approximate value observed in the U.S. We also assume that government spending in each sector is equal to this aggregate share so that $\frac{g_{d}}{y_{d}}=\frac{g_{h}}{y_{h}}=0.2$. Finally, we set $d=100, k_{0}=5$ and $A_{0}=1$. This allows us to consider situations where natural resources are relatively plentiful, where by relatively plentiful we mean that environmental resources are in relatively greater supply than the physical capital

\footnotetext{
${ }^{8}$ The upper limit of this feasible range is chosen such that the implied capital elasticity is equal to the natural resource elasticity. Values of $\eta$ beyond this limit seem unreasonable as they would imply natural resources as more productive than capital.
} 
stock (i.e., $d=100$ and $k_{0}=5$ ), as well as situations in which they are in relatively less abundance, where by relatively less abundant we mean that environmental resources are in relatively lesser supply than physical capital (i.e., when $k$ passes $d=100$ ). We refer to situations in which resources are relatively plentiful as less developed periods which occur during the initial dates of our simulations and to situations in which they are less abundant as developed periods which occur during later dates of our simulations when the capital stock has grown larger than the natural resource stock.

\section{Policy Implications}

This section presents the optimal policy results. The results are organized into three subsections in order to provide greater clarity. The first subsection discusses the dynamic aspects of fiscal policy in a growing economy. Here results of the Ramsey planning outcome are plotted for an exogenously growing capital stock under various degrees of substitution between arguments in the utility function. This analysis provides intuition into how each parameter impacts optimal tax policy. Of primary interest is how the dynamic optimal tax profile is impacted by different values for the elasticity of substitution between leisure and resource amenities, $\sigma$, and different values for the elasticity of substitution between dirty goods and clean goods, $\psi$. The second subsection extends the analysis to show that situations in which non-monotonic policy behavior can arise under certain specifications for the utility elasticities. Finally, the last subsection develops an application of the model to local community growth incentives, a context in which non-monotonic policy is commonly observed.

\subsection{Utility elasticities and dynamic optimal policy}

Here we investigate how the three utility elasticity parameters impact tax policy in a developing economy. We do this by exploring how incremental changes in the value of the utility elasticity parameters, $\sigma, \psi$ and $\theta$ change the time path for optimal taxes. These results are summarized by the pattern of optimal dynamic tax rates in Figures 
1-3. In these figures we have adopted the convention of plotting the capital stock $k$, rather than time $t$, along the horizontal axis. Since capital grows at the constant rate given by (2), we see that $k$ could be transformed into $t$ and time plotted instead. We chose to plot $k$ in order to highlight some intuition in our discussion below for when turning points in dynamic tax policy arise. ${ }^{9}$

To understand the policy role of the Ramsey planner, notice that the baseline value of $\gamma=0.5$ implies incomplete property rights over environmental resources devoted to amenity production. Absent policy, amenity values are undersupplied in the economy. Accordingly, the Ramsey planner desires to increase the supply of environmental resources allocated to amenity services and decrease the supply of environmental resources devoted to the production of dirty goods. This corrective role of taxes implies that the Ramsey planner selects a higher tax on the dirty good than on the clean good.

Next, consider the dynamic aspects of policy as the economy grows. As economic growth takes place, the capital stock and the effective labor supply increase over time, but the level of the environmental resource remains fixed at $d=100$. Consequently, the value of the environmental resource in dirty production is bid up over time. Balancing this effect is the increase in amenity value of the environmental resource because of its connection to effective leisure which is also growing. The optimal allocation of the environmental resource is determined by the interaction of these competing interests. The dynamic nature of optimal tax policy is thus influenced by the degree to which the alternative uses of the environmental resource are complementary or substitutable with other arguments in the utility function.

Figure 1 plots the optimal dynamic tax profile for different degrees of complementarity between amenity values and leisure, $\sigma$. Notice in Figure 1a that when amenity values are more complementary with leisure, the optimal tax on dirty goods increases over time, while the opposite occurs when amenity values substitute for leisure. In

\footnotetext{
${ }^{9}$ One could also interpret these exercises as illustrating how taxes respond to capital levels in a static setting.
} 
the case of complementary values, a rise in effective leisure over time facilitates consumer demand for amenities, and the amenity value of environmental resources goes up more quickly than the value of environmental resources in dirty good production. The planner responds by steering resources away from dirty good production and towards use in amenity by raising the tax on dirty goods. The opposite occurs when leisure and amenity values are substitutes. In this case, increased leisure over time facilitates substitution possibilities between leisure and amenity values, and the production value of resources rises more quickly than resource amenity values. The Ramsey planner responds by guiding environmental resources towards production by lowering the tax on dirty goods over time.

\section{Put Figures 1A AND 1B Here.}

Figure $1 b$ indicates an outcome for the tax on the clean good that mirrors that of the dirty good tax. This outcome reflects the planner's need to raise a constant share of output as tax revenue so that, in general, taxes on clean goods decline (increase) with larger (smaller) taxes on dirty goods. Because of this connection between the two tax rates, in Figures 2 and 3 we consider only the dynamic pattern of taxes on dirty goods and allow the tax on clean goods to remain implicit.

It is also possible to evaluate what is happening to other variables in the equilibrium. We now present some of this analysis without figures as the results are mostly intuitive. Furthermore, since this analysis moves us away from the tax analysis, which is the main focus of the paper, we only present them here for the alternative $\sigma$ value cases and leave them implicit in the other cases considered below. Regardless of the elasticity parameters, the production, and thus the consumption, of both the dirty and clean goods increase over time as the level of technology increases. Because the dirty good has a factor of production which is limited, dirty output and consumption growth is somewhat slower than clean output and consumption growth. Because of the relative scarcity of the dirty good, its price relative to the clean good is always increasing over time. Furthermore, for most elasticity values, the price 
increase of the dirty good is sufficiently fast that the share of consumer expenditures on dirty goods actually increases over time.

Figure 2 depicts the dynamic optimal tax profile for variations in the elasticity of substitution between consumption of dirty goods and clean goods, $\psi$. For more substitutable values of $\psi$, the optimal tax on dirty goods rises over time, and the tax increases at a faster pace as substitutability gets higher. Under circumstances in which clean goods can be readily substituted for dirty goods in utility, the cost of allocating environmental resources to dirty good production rises because of the relatively faster increase in the ability to produce clean goods. The Ramsey planner responds by encouraging fewer dirty goods by raising taxes on them. On the other hand, when consumption goods are highly complementary, the opposite occurs: taxes on the dirty good fall over time. This is because the utility value of dirty goods rises faster than the amenity value as economic growth increases consumption of clean goods. This means the planner reduces taxes on dirty goods over time to redirect resources into dirty good production.

\section{Put Figures 2 and 3 Here.}

Figure 3 shows the optimal tax path for incremental changes in the elasticity of substitution between the consumption good aggregate, $c$, and the leisure-amenity aggregate, $b$. These figures exhibit similar characteristics as those in Figure 2, although the tax on dirty goods is higher in all periods for greater values of the substitution parameter between goods, $\psi$, than they are for greater values of $\theta$. This is because a higher degree of substitution arising from $\psi$ values allows the tax to be more focused on the dirty good than a higher degree of substitution arising from $\theta$ does.

\subsection{Substitutable utility arguments and non-monotonic policy}

Here we show that optimal policy in both the dirty goods and clean goods sector need not follow monotonic paths over time. We demonstrate this with simulations in 
which dirty goods and clean goods are highly substitutable and vary the substitution possibilities between leisure and amenity values. These results are illustrated in Figures $4 \mathrm{a}, 4 \mathrm{~b}$ and $4 \mathrm{c}$ where the elasticity parameter $\theta$ was left at its baseline and $\psi$ was set to 0.7 to reflect a high level of substitutability while $\sigma$ was allowed to range from a complementary value of -0.9 to a substitutable value of 0.7 . Figure 4 a shows a reversal in the tax on dirty goods occurs when $\sigma=0.7$, which reflects a high level of substitutability, while Figure $4 \mathrm{~b}$ shows a reversal in the tax on clean goods occurs when $\sigma$ reflects a high degree of complementarity. ${ }^{10}$ For this discussion we will also find it useful to refer to Figure 4c which shows how much of the natural resources are allocated to production.

\section{Put Figures 4A, 4B And 4C here.}

First consider the case where there is a reversal in the tax rate on dirty goods (i.e. the $\sigma=0.7$ case). In early periods of a growing economy, resources are relatively plentiful, where by relatively plentiful we mean that resources are in relatively greater supply than the physical capital stock (i.e., $d=100$ and $k_{0}=5$ ). Because of the low initial capital stock and effective labor supply levels, natural resources are not very productive and because dirty goods and clean goods are close substitutes, the best use of the resource for generating utility is in amenity as illustrated in Figure 4c. To assist in allocating the natural resource toward amenity, optimal taxes on dirty goods are kept relatively high. As the economy grows, the capital stock and effective labor supply grow and this pushes up the value of resources in dirty good production. This rise in the value of resources in production is sufficiently fast that resources shift quickly into production and away from amenity. This movement away from amenity increases the amenity externality and the Ramsey planner attempts to slow this reallocation by raising taxes on dirty goods further. However, after a point, these taxes reverse and start to fall. The point where taxes start to fall occurs approximately

\footnotetext{
${ }^{10} \mathrm{It}$ is also possible to have non-monotonic tax time paths opposite to these with a different set of paramters. So for instance, it is possible to have dirty good taxes initially fall for a period of time and after a while turn and then start rising. These cases are not presented here.
} 
when natural resources might be described as becoming less abundant than the capital stock (i.e. approximately when $k$ passes $d=100$ ). Alternatively, one might say this turning point occurs when capital and effective labor are in relatively greater abundance than natural resources. With this increase in the capital and effective labor inputs in production, resources become increasingly valued in production and because of the high degree of substitutability between amenity and leisure the planner finds it desirable to facilitate the movement of the natural resource into dirty good production by lowering dirty good taxes and financing expenditures increasingly on taxes from clean goods as seen in Figure $4 \mathrm{~b}$.

Next consider the case where there is a reversal in the tax rate on clean goods (e.g. the case where $\sigma=-0.9$ ). Figure $4 \mathrm{~b}$ shows that the initial periods are marked by a falling tax on clean goods which eventually reverse and starts to increase right around the point where natural resources might be described as less abundant (i.e. approximately when $k$ becomes larger than $d=100$ ). To understand this case intuitively, note that during the initial periods when natural resources are relatively plentiful, resources are predominately allocated to production (See Figure 4c). This is because the small $\sigma$ reflects complementarity and thus it is best to have more equal values of amenity and leisure in the early stages of development. Since effective leisure is small, because of the low technology level, amenity needs to be small as well, so taxes on dirty goods are initially lower in this complementary case than in the substitutable case described above. As the capital stock and effective labor supply grow, resources are replaced in production by capital and labor and move into amenity where they need to increase because of the complementarity with effective leisure which is growing with the rising technology level. To help guide this movement of resources into amenity, Figure 4a shows the social planner raising taxes on dirty goods which allows it to reduce taxes on clean goods for a while. As resources start to become relatively less abundant (i.e. approximately when $k$ becomes larger than $d=100$ ), the planner finds that it needs to continue increasing taxes on dirty goods to further encourage resources into amenity where it is complementary to leisure. 
However, because consumption goods are substitutable, the tax increases on dirty goods slows their production enough that the planner finds that it needs to start raising taxes on clean consumption goods so as to balance its budget constraint.

\subsection{Application: Community development patterns}

In the United States, local government policies often exhibit non-monotonic behavior toward development over time. In particular, it is not uncommon for local governments to adopt a pro-growth position at early stages of community development in which building permits are easily obtained and tax incentives are provided to attract businesses. This high growth period is then sometimes followed by a slow growth, or in some extreme cases a no growth period, in which building permits are more difficult to obtain, which is then followed by a reopening of development to moderate growth in which building permits become somewhat easier to obtain than the recent past. It is useful to emphasize, that this non-monotonic policy is only observed in some communities. However, in those that it is observed, an interesting question is whether such an observation could be the result of an optimal policy maker.

The non-monotonic pattern of local community development described above is consistent with the illustration in Figures $4 \mathrm{a}, 4 \mathrm{~b}$, and $4 \mathrm{c}$ in which $\psi=0.7$ and $\sigma=0.7 .^{11}$ In the early "development phase", which corresponds to low capital values in the figures above, taxes are low on the natural resource based good (development), where we interpret the tax as the local development impact fee on new construction and the dirty good as homes built on undeveloped land. This initial period is then followed by one in which development impact fees rise, which is reflected by the high tax rate on the dirty good. Finally, this slow growth policy stance gives way to a more moderate growth policy stance in which development becomes somewhat less costly, as reflected by the lower tax rate on the dirty good. In interpreting our model in this way, it is important to note that although the model shows that the policy variable can exhibit a non-monotonic pattern, the actual use of land for amenity, as

\footnotetext{
${ }^{11}$ Here we focus on the case in which growth only slows in the middle period rather than being fully choked off to the point of no growth.
} 
well as production of the dirty good, is monotonic in a way that shows a continuously decreasing percentage of land being used for amenity and a continuously increasing percentage of land being used for housing.

Furthermore, our model provides insight into which types of communities experience monotonic behavior as a result of optimal policy and which do not. Holding $\psi=0.7$, we see that communities with somewhat lower elasticities of substitution between amenity and leisure, for instance $\sigma=0.3$, are likely to experience monotonic behavior while those with higher elasticities, such as $\sigma=0.7$, do not. Put differently, the more willing a community is to trade off amenity values and leisure, the more likely there will be non-monotonic building permit policy for development.

\section{Conclusion}

This paper investigated the dynamic tax policy decisions of a Ramsey planner who designs policy to allocate an environmental resource between alternative uses in the production of goods and the production of amenity values in a growing economy with a rich set of consumer utility arguments. The analysis reveals that elasticities of substitution between consumer utility arguments impact the dynamic behavior of optimal tax policy. The substitution elasticities between environmental resource amenity and leisure and between dirty goods and clean goods have the most pronounced impact on the dynamic policy profile. The reason for this is that as the economy grows, the marginal valuation of the various utility arguments are impacted unequally. Under circumstances where amenity value is complementary with leisure, growth in leisure increases demand for environmental resource amenities, and the optimal policy adjusts by increasing taxes on dirty goods over time to steer resources towards the production of amenity values. Conversely, when amenity values and leisure are substitutes, growth in effective leisure over time causes consumers to substitute away from amenity values in utility, and the optimal tax profile involves declining taxes on dirty goods over time. Under circumstances where dirty goods and clean goods are substitutes, taxes on dirty goods increase over time with the growth in capital being 
allocated increasingly to clean production techniques, as consumers are better able to replace dirty good consumption with consumption of clean goods.

One interesting outcome occurs when there is a high degree of substitution between amenity value and leisure and between dirty and clean goods. In this case, taxes on dirty goods may rise for a period of time to capitalize on the ability for dirty goods to substitute for clean goods, but then to subsequently fall as the growth in leisure facilitates substitution away from amenity values in utility. This complexity of the dynamic optimal tax problem highlights the need to carefully understand the relationship between environmental values and clean goods in consumer utility functions. Understanding this relationship is particularly important for environmental resources that have dual uses. Moreover, these results show that environmental policy need not be generic, but instead should reflect the individual aspect of amenities provided by a particular environmental resource. For instance, forest resources may be characterized by more complete property rights than fishery resources, but also provide a greater degree of complementarity with leisure. Optimal dynamic policies on forest and fishery resources should reflect these differences. 


\section{References}

[1] Aiyagari, S.R., Marcet, A., Sargent, T., and Seppälä, J. 2002. Optimal taxation without state-contingent debt. Journal of Political Economy 110, pp. 1220-1254.

[2] Auerbach, A.J., and Hines, J.R. 2001. Taxation and economic efficiency. NBER Working Paper No. 8181, March 2001.

[3] Bovenberg, A.L. and Goulder, L.H. 1996. Optimal environmental taxation in the presence of other taxes: General-Equilibrium analyses. American Economic Review 86, pp. 985-1000.

[4] Bovenberg, A.L. and Goulder, L.H. 2002. Environmental taxation and regulation. Handbook of Public Economics Vol. 3, pp. 1471-1545.

[5] Bovenberg, A. L. and de Mooij, R. A. 1997. Environmental tax reform and endogenous growth. Journal of Public Economics 63, pp. 207-237.

[6] Bovenberg, A.L. and van der Ploeg, F. 1994. Environmental policy, public finance and the labor market in a second-best world. Journal of Public Economics 55 , pp. 349-90.

[7] Cassou, S.P. and Hamilton, S.F. 2005. The transition from dirty to clean industries: Optimal fiscal policy and the environmental Kuznets curve. Journal of Environmental Economics and Management 48, pp. 1050-77.

[8] Cassou, S.P. and Lansing, K.J. 1998. Optimal fiscal policy, public capital, and the productivity slowdown. Journal of Economic Dynamics and Control 22, pp. 911-935.

[9] Cassou, S.P. and Lansing, K.J. 2006. Tax reform with useful public expenditures, forthcoming in Journal of Public Economic Theory.

[10] Chamley, C. 1986. Optimal taxation of capital income in general equilibrium with infinite lives. Econometrica 54, 607-622.

[11] Chari, V.V., Christiano, L.J. and Kehoe, P.J. 1994. Optimal fiscal policy in a business cycle model. Journal of Political Economy 102, pp. 617-652.

[12] Dasgupta, S., Laplante, B., Wang, H. and Wheeler, D. 2002. Confronting the environmental Kuznets curve. Journal of Economic Perspectives 16, pp 147-168.

[13] Gorostiaga, A. 2003. Should fiscal policy be different in a non-competitive framework? Journal of Monetary Economics 50, pp. 1311-1331.

[14] Gorostiaga, A. 2005. Optimal fiscal policy with rationing in the labor market. Topics in Macroeconomics 5, No. 1, Article 17.

[15] Goulder, L.H. 1995. The effect of carbon taxes in an economy with prior distortions: An intertemporal general equilibrium analysis. Journal of Environmental Economics and Management 29, pp. 271-97.

[16] Jones, L.E., Manuelli, R.E., and Rossi, P.E. 1993. Optimal taxation in models of endogenous growth. Journal of Political Economy 101, pp. 485-517.

[17] Jones, L.E., Manuelli, R.E., and Rossi, P.E. 1997. On the optimal taxation of capital income. Journal of Economic Theory 73, pp. 93-117. 
[18] Jorgenson, D.W. and Wilcoxen, P.J. 2003. Reducing US Carbon Emissions: An Econometric General Equilibrium Assessment, Resource and Energy Economics $15(1), 7-25$.

[19] Judd, K.L. 1985. Redistributive taxation in a simple perfect foresight model. Journal of Public Economics 28, pp. 59-83.

[20] Judd, K.L. 1999. Optimal taxation and spending in general competitive growth models. Journal of Public Economics 71, pp. 1-26.

[21] Lopez, R. 1994. The environment as a factor of production: The effects of economic growth and trade liberalization. Journal of Environmental Economics and Management 27, pp. 163-84.

[22] Lucas, R.E., Jr., and Stokey, N. 1983. Optimal monetary and fiscal policy in an economy without capital. Journal of Monetary Economics 12, pp.55-94.

[23] Poterba, J.M. 1993. Global warming: A public finance perspective. Journal of Economic Perspectives 7, pp. 47-63.

[24] Ramsey, F.P. 1927. A contribution to the theory of taxation. Economic Journal 37, pp. $47-61$.

[25] Sandmo, A. 1975. Optimal taxation in the presence of externalities. Swedish Journal of Economics 75, pp. 86-98.

[26] Zhu, X. 1992. Optimal fiscal policy in a stochastic growth model. Journal of Economic Theory 58, pp. 250-289. 

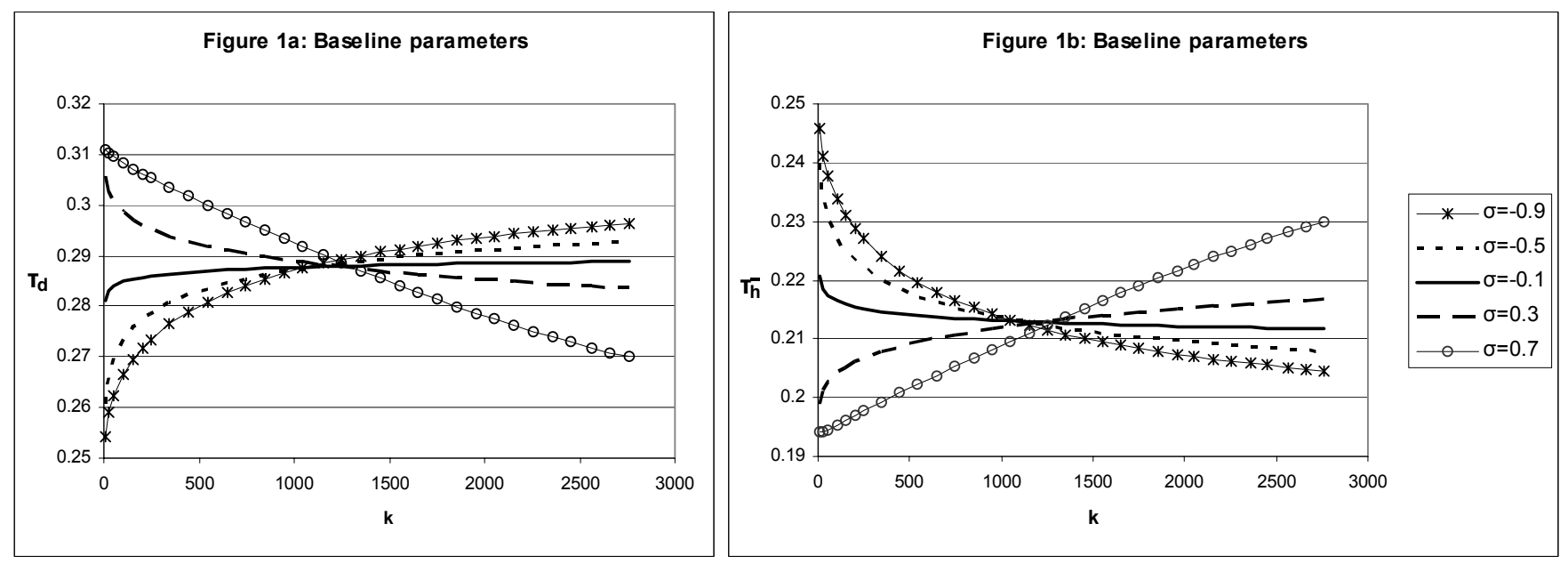

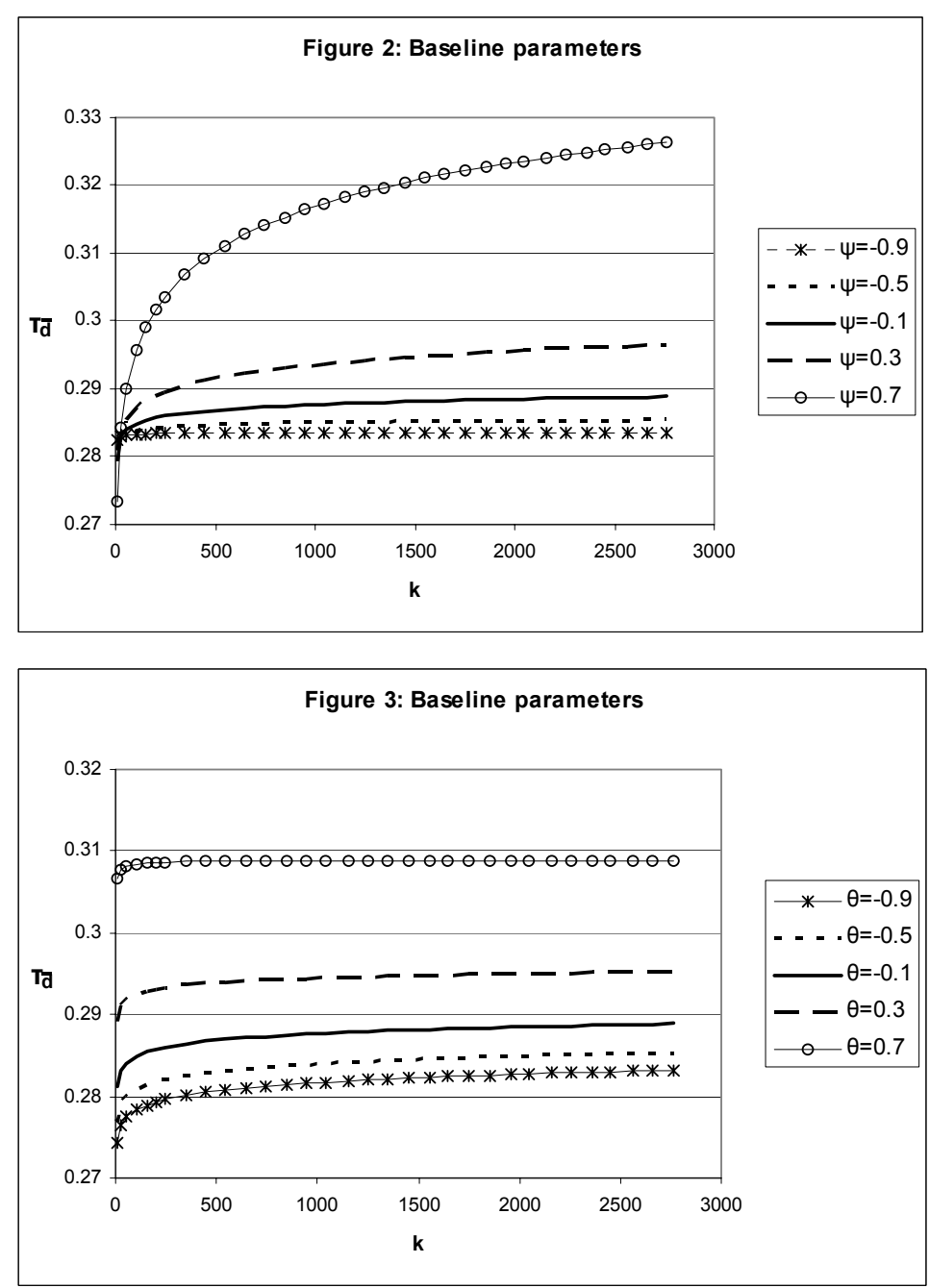

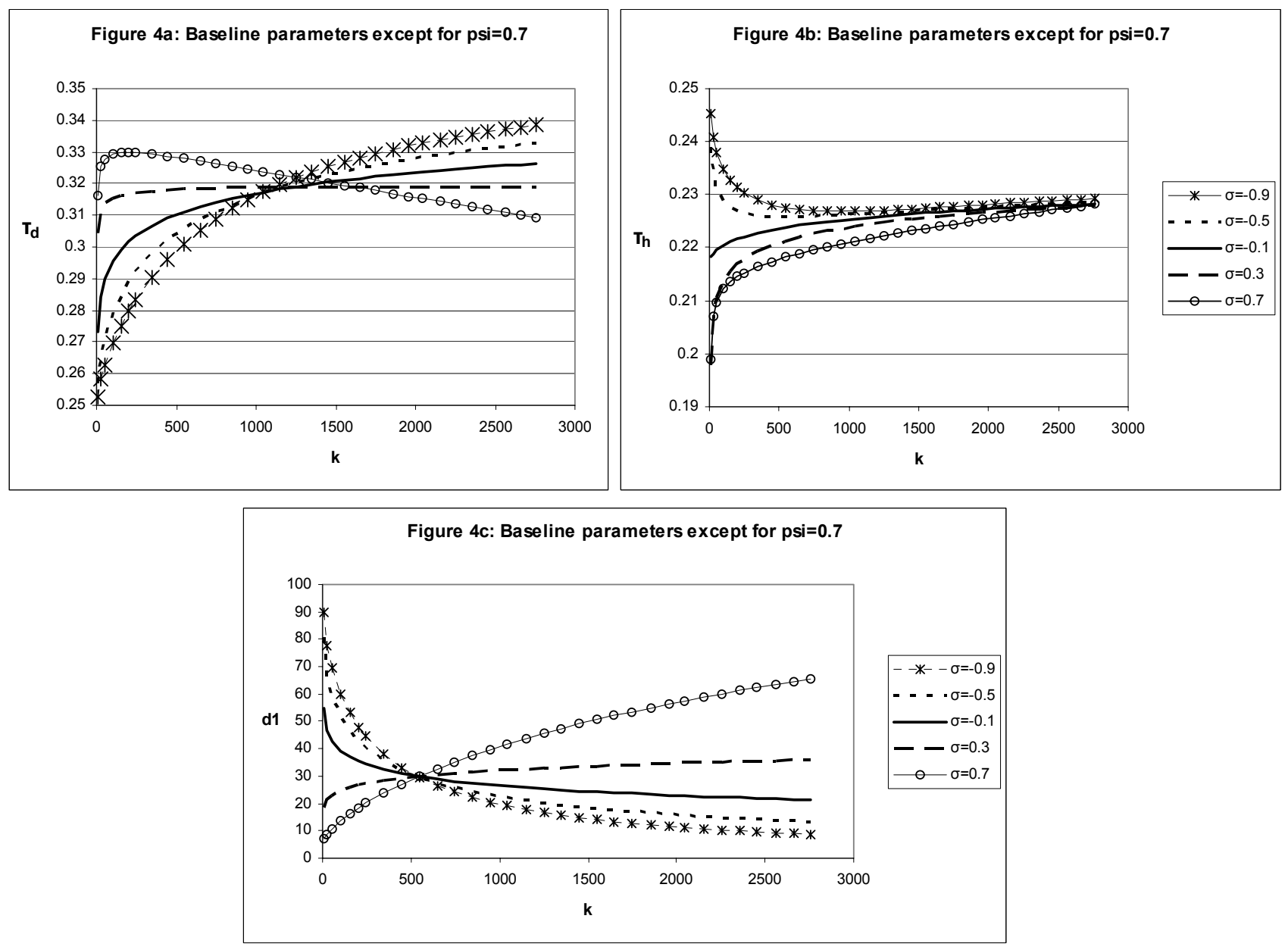